\title{
Gordon C. Hillman
}

\section{July 1943 to 1 July 2018}

\author{
Andrew Fairbairn and Mark Nesbitt \\ The University of Queensland, Australia, and Royal Botanic Gardens, Kew, UK \\ m.nesbitt@kew.org
}

$\mathrm{G}^{\mathrm{s}}$ ordon Hillman transformed the field of archaeobotany, developing its key research questions and methodology between the 1970s and 1990s. He brought novel approaches to the interpretation of archaeological plant remains from farming sites, in particular to the transition from foraging to farming, that still frame the debate on this subject. His work became influential through numerous publications and the global dispersal of his students from University College London (UCL), where he was based from 1981.

Turkey, and the British Institute of Archaeology at Ankara (as it was then called), played a key role in the development and spread of Gordon's ideas. After a year's training in seed identification with Maria Hopf in Mainz, he arrived in Turkey in 1969 to join David French's excavations at Canhasan III on the Konya plain. Here, through the inspiration of Sebastian Payne, one of the first flotation machines had been built. It enabled the recovery of large amounts of seeds, charcoal and bone, even from early (in this case Pre-Pottery Neolithic B) sites with a low density of charred plant remains.

From 1970 to 1973 Gordon joined excavations at the village of Aşvan, due to be flooded by the Keban Dam in eastern Turkey. Here French was pioneering a new kind of excavation, incorporating excavation across four sites to ensure temporal continuity, and with equal emphasis given to the recovery of artefacts and ecofacts. The most novel component, later to be heavily criticised by some members of the archaeological establishment, was the study of the modern life of the village through the methodologies of disciplines such as geography and anthropology.

There were few machines in the village, offering an opportunity to study traditional agricultural techniques. The resulting ethnoarchaeological studies of animals (by Sebastian Payne) and plants (by Gordon) have both proved to be highly influential. Gordon had a natural rapport with Turkish farmers - he had worked on Sussex farms as a youth - and quickly learnt Turkish. His observations of traditional crop processing - later to be the subject of elaborate flow charts that echo the chaîne opératoire included quantified studies of products and by-products of cereal harvests. These showed that the proportions and types of seed, chaff and crop were closely correlated with the stage of crop-processing, and that these stages could equally be identified in archaeological samples. Analysis of samples in terms of crop-processing now forms a standard part of archaeobotanical methodology worldwide.

The Canhasan III and Aşvan excavations also introduced Gordon to the importance of understanding local vegetation. The Flora of Turkey was only half-complete on his arrival, so plant identification depended heavily on his excellent field botany, honed during five years in the European herbarium of the Natural History Museum and a subsequent degree in agricultural botany at the University of Reading. Initial excursions were to Karadağ on the Konya plain and around Aşvan, particularly the rocky slopes near Çemişgezek where oak trees and wild cereals grew. Later trips, with the support of project funding, were more ambitious. In 1983 he, David Harris and Sue Colledge travelled in Syria, looking at wild cereals, and then eastern Turkey, studying emmer cultivation. It was on this trip that the party was arrested and invited to stay overnight in a military camp while their credentials were investigated. A second long trip to eastern Turkey followed in 1992 with Harris and the Israeli botanist Daniel Zohary.

Gordon's plant collections were recorded, with much detail on habitat, on sheets specially printed in Ankara. His seed collection and herbarium, including excellent representation of cereal landraces, is one of his most important legacies at the British Institute at Ankara (BIAA), as are its excellent library holdings on Near Eastern botany and agriculture. Verification of herbarium specimens using the completed Flora of Turkey was finalised in 1989 by Fred Rumsey. The seed collection is duplicated at the Institute of Archaeology, UCL, and formed the basis of Gordon's meticulous approach to seed identification. 
In 1972 Gordon joined Andrew Moore's excavations at Abu Hureyra in Syria. As at Aşvan, the site was to be flooded by a dam on the Euphrates. The $8 \mathrm{~m}$ of deposits spanned about 4,000 years of human occupation, and the transition from foraging to farming. Gordon applied the same bulk flotation techniques used at Canhasan III and Aşvan to the site, recovering over 500 litres of plant remains that formed the main focus of his work until the publication of the final report in 2000 .

Although important publications were based on his Aşvan ethnoarchaeology, Gordon's interests moved away from Turkey in the 1980s and 1990s, both towards Abu Hureyra and to other important sets of plant remains including those from Wadi Kubbaniya in Egypt and Jeitun in Turkmenistan. However, his students were to develop work in Turkey much further. George Willcox was Gordon's first student, working on the charcoal from Canhasan III and Aşvan. As a researcher in the French Centre national de la recherche scientifique (CNRS), Willcox became the leading archaeobotanist of early sites in the Near East. Glynis Jones, founder of the archaeobotany programme at the University of Sheffield, met Gordon while a student at Cardiff, where Gordon taught for six years after returning from Turkey. Her ethnoarchaeological work in Greece, inspired by the Aşvan studies, developed the statistical framework in which cropprocessing is now usually studied.

From 1985-1990 and 1997-1998 Mark Nesbitt, a postgraduate student at the Institute of Archaeology, was a research fellow at the BIAA, building flotation machines at sites including Dilkaya and Hallan Çemi in eastern Turkey, advising on recovery at many other sites and augmenting the seed reference collection, which was reorganised by him and Amanda Kennedy in 1997-1998. This secured the collection's future, and interest in its use grew as a new generation of archaeobotanical scholars emerged in Turkey, many associated with a fresh wave of Neolithic research. Ann Butler, another of Gordon's students, built the first flotation machine at Çatalhöyük, where Julie Near and Andy Fairbairn were among those publishing archaeobotanical results from the site. As well as supporting the work of foreign scholars, in the new millennium the BIAA, including its archaeobotany reference collection, has been a key resource for the first generation of Turkish archaeobotanists, many with direct connections to Gordon and/or his students. Among them, Füsun Ertuğ undertook wide-ranging ethnobotanical research and applied it to the archaeobotany of Aşıklı Höyük; Emel Oybak Dönmez began a career in archaeobotany that now spans the country; Aylan Erkal undertook research at Çatalhöyük East; Ceren Kabukcu developed wood charcoal analysis of the Neolithic transition on the Konya plain and Cemre Üstünkaya investigated Bronze and Iron Age agricultural change.

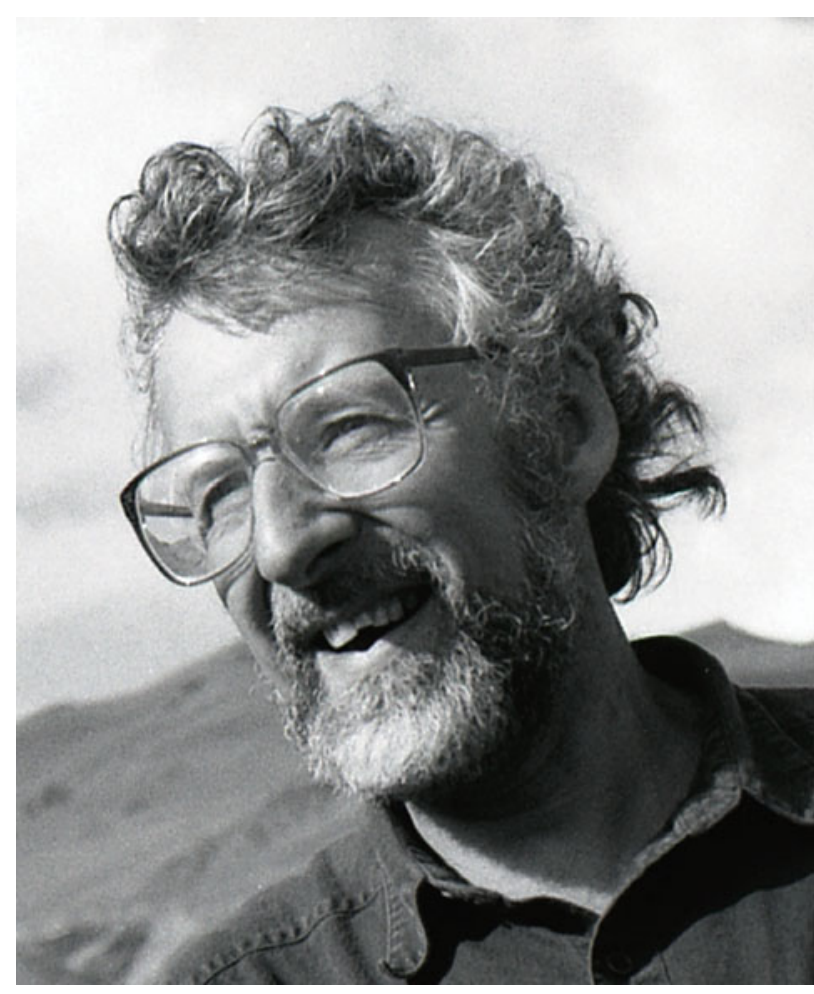

Gordon Hillman in Turkey in about 2000. Photograph by Thilaka Hillman

The considerable archives of charred plant remains collected from Gordon's excavations continue to be studied and published. They include the recent publication of the ground-breaking study at Aşvan by Nesbitt and colleagues, and publication projects in process by Fairbairn on the archaeobotany of Canhasan III.

Gordon Hillman leaves an enduring legacy in world archaeobotany, but his foundational work and experiences were in Turkey. His application of bulk flotation/sieving and his innovative interpretations of seed assemblages established that archaeobotany is a feasible, worthwhile and central element of archaeological excavation method. In some ways, the unexpected richness of the application of those techniques in Turkey in the 1970s overwhelmed his own capacity to analyse the resultant tidal wave of material they unleashed. It says much for Gordon's commitment that he continued to work on these projects and their publication until his death. He leaves behind an archive that will be available to future generations of scholars. Gordon's approach emphasised the enduring value of identification and analysis based on rigorous criteria and proper reference collections, brought to life by a human-centred understanding of the value of plants and their many uses. Ultimately, his greatest achievement may well be the simple understanding that it is real humans who were gathering or farming, not abstract figures, and that through systematic investigation those real humans can be understood, even in the most distant and obscure phases of the human past. 